\title{
DNA identification of Leishmania (Viannia) braziliensis in human saliva from a patient with American cutaneous leishmaniasis
}

\author{
Corvalan FH (1), Sampaio RNR (2), Brustoloni YM (3), Andreotti R (4), Lima Júnior MSC (5)
}

\begin{abstract}
(1) Department of Special and Community Dentistry, School of Odontology. Federal University of Mato Grosso do Sul, Campo Grande, Mato Grosso do Sul State, Brazil; (2) Laboratory of Dermatology, Department of Clinical Medicine, School of Medicine, University of Brasilia, Brasília, Federal District, Brazil; (3) Department of Pediatrics, School of Medicine, Federal University of Mato Grosso do Sul, Campo Grande, Mato Grosso do Sul State, Brazil; (4) Molecular Biology Laboratory, EMBRAPA Beef Cattle, Campo Grande, Mato Grosso do Sul State, Brazil; (5) Doctoral Program of Infectious and Parasitic Diseases, Federal University of Mato Grosso do Sul, Campo Grande, Mato Grosso do Sul State, Brazil.
\end{abstract}

\begin{abstract}
This study aims to report the amplification of the DNA of Leishmania $(V$.$) braziliensis, using$ polymerase chain reaction, obtained from the saliva of a patient with American cutaneous leishmaniasis who did not present any lesion in the oral mucosa. Amplification produced fragments of $103 \mathrm{bp}$, an estimated size employing Leishmania $(V$.) braziliensis primers (b1 e b2). The present results revealed, for the first time, that the in vitro amplification of Leishmania DNA using samples from the salivary fluid of a patient with American cutaneous leishmaniasis is possible. However, more studies are required with a larger number of participants to evaluate the usefulness of saliva as a non-invasive sample for PCR. The development of such non-invasive technique is necessary for the diagnosis of many diseases in the future, especially infectious and parasitic ones.
\end{abstract}

Key words: cutaneous leishmaniasis, saliva, Leishmania, polymerase chain reaction, non-invasive diagnosis.

\section{INTRODUCTION}

Leishmaniasis, a disease that affects humans, is caused by different species of parasites that can be differentiated only by biochemical, immunological, molecular and pathological methods. Sensitivity its capacity of detecting microorganisms - and the speed with which the identification of the parasite can be made comprise the main advantages of techniques based on DNA detection.

Advances in molecular biology have enabled the development of specific tools for diagnosing various diseases, allowing the establishment of a more precise diagnosis and prognosis $(1,2)$. Among the molecular methods that have been developed with high sensitivity and specificity that can be applied in taxonomy diagnosis, the polymerase chain reaction (PCR) is presented as an option in diagnosis of leishmaniasis (3-5). It has the potential of becoming an additional diagnostic tool, allowing the establishment of a correct diagnosis and a more precise prognosis.

It has been reported in the literature that it is possible to detect the causative agent of the visceral leishmaniasis (VL) in tissue samples, blood, urine, feces and swabs of human nasal and oral secretions (6). However, there are no records in the medical literature concerning the presence of etiologic agents of American cutaneous leishmaniasis (ACL) in the oral fluids, thus, the objective of the present study was to use molecular methods such as PCR to detect Leishmania in these secretions. Knowing of the high sensitivity and specificity of PCR, this molecular tool was employed to verify the possibility of detecting Leishmania DNA in the saliva of a patient with clinical diagnosis of ACL. Because of the complex diagnosis of the disease, the detection of Leishmania DNA in saliva could be an option in the parasitological investigation $(7,8)$. 
The current study presents the case of a 35 years old individual from a rural area (farmer), who in August 2007 showed a skin lesion on the left calf and the temporal region. The Montenegro skin test was positive and clinical cure was obtained with the use of $\mathrm{N}$-methylglucamine, $20 \mathrm{mg} / \mathrm{kg} /$ day for 20 days. Nine months later, the patient returned with skin lesions on the face, distributed next to the left angle of the mouth, on right and left pre-auricular region, on the chin and on the right lateral neck; however, there were no lesions in the oral mucosa (Figure 1).

Besides the patient with ACL, six other patients with VL and a healthy subject (whose saliva was collected and included in the reaction) were also tested.

The oral fluid was collected during the medical examination of the patients, put in a $1.5 \mathrm{~mL}$ sterile Eppendorf microtube, and frozen at $-20^{\circ} \mathrm{C}$ until the DNA extraction. The DNA extraction method employed phenol/chloroform and precipitated with ethanol $(4,9)$.

\section{POLYMERASE CHAIN REACTION}

Primers described in the literature were used in the PCR. The reaction was standardized by the Laboratory of Molecular Biology of the Federal University of Mato Grosso do Sul, according to Lima Júnior et al. (10). The DNA samples used as controls were provided by the Leishmaniasis Laboratory of the Research Center René Rachou/ Fiocruz (Belo Horizonte, Brazil): L. (L.) chagasi (MHOM/BR/74/PP/75), L. (L.) amazonensis (IPLA/BR/67/PH8) and L. (V.) braziliensis (MHOM/BR/75/M2903), taking into account the expected product size and annealing temperatures of primers. For L. (L.) chagasi the primers used were RV1 (CTTTTCTGGTCCCGCGGGTAGG) and RV2 (CACCTGGCCTATTTTACACCA), with the expected product of $145 \mathrm{bp}$; for L. (L.) amazonensis the primers were al (TGCGAGGATAAAGGGAAAGAA) and a2 (TGCCCTGACTTGCATGTCTA), with the expected product of $62 \mathrm{bp}$; and for $L$.

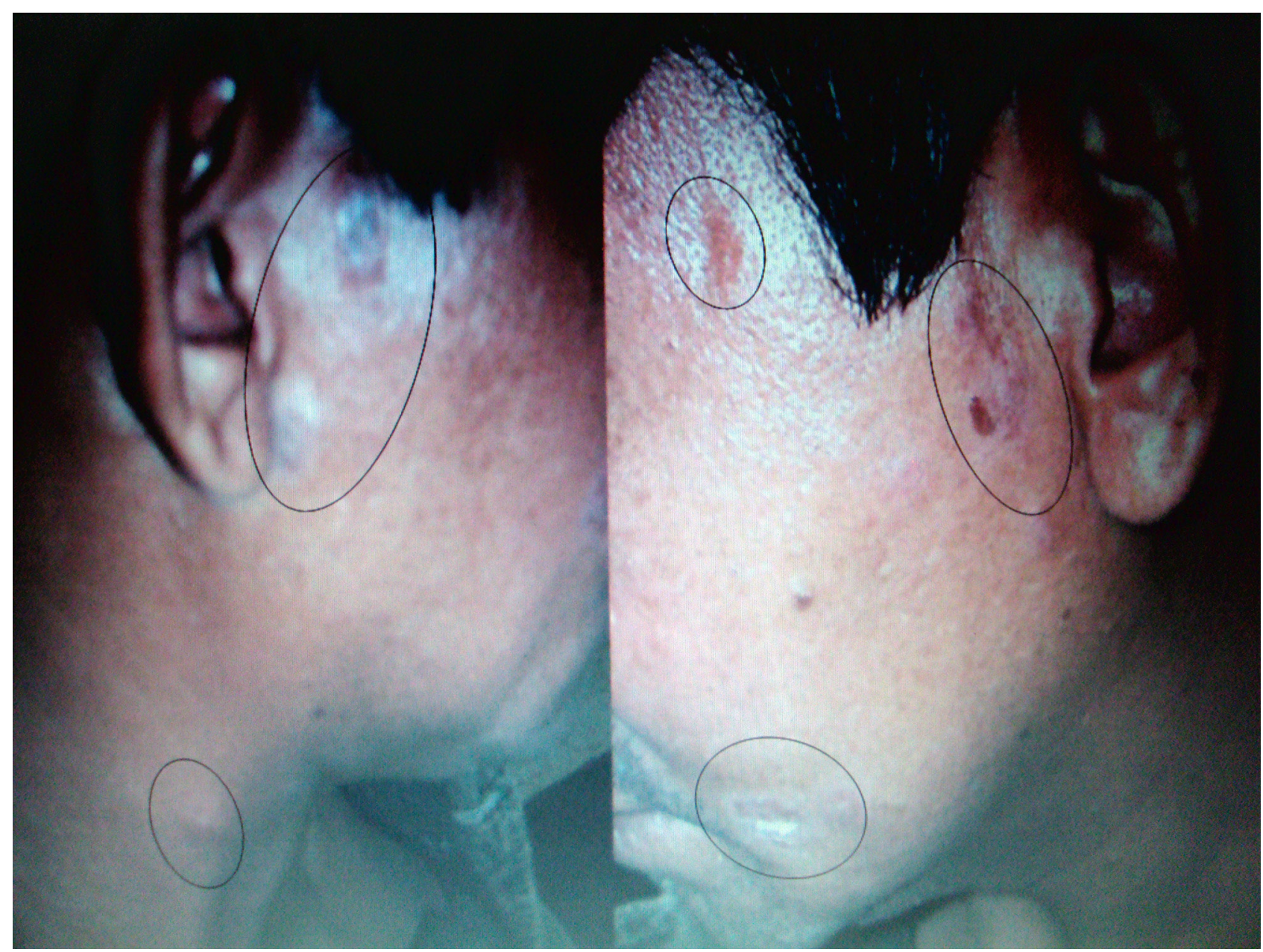

Figure 1. The patient showing papular lesions on pre-auricular regions and on the right cervical region, a scaly lesion on the left angle of the mouth and a pustular lesion on the chin. 
(V.) braziliensis, the primers used were b1 (GTGGGCGTATCTGCTGATGAC) and b2 (CAAAAAGCGAGGGACTGCGGA), with the expected product of $103 \mathrm{bp}$. These data are displayed in Table 1.

\section{PCR Conditions}

- With a volume of $25 \mu \mathrm{L}$ RV1/RV2: Phoneutria 2X buffer (Phoneutria Biotecnologia e Serviços Ltda., Brazil) , $0.2 \mathrm{mM}$ dNTPs, 0.3 $\mathrm{mM} \mathrm{MgCl}, 0.16 \mathrm{pmol} \mathrm{RV1/RV2} \mathrm{primers,} \mathrm{Taq}$ polymerase $4 \mathrm{U}$ (Phoneutria Biotecnologia e Serviços Ltda., Brazil), 0.5 of mL DNA, 19.4 of $\mathrm{mL}$ water and thermal cycler BIOER XP (BIOER Techonology Co. Ltda., China). The cycle conditions were $95^{\circ} \mathrm{C}$ for five minutes, 40 cycles at $94^{\circ} \mathrm{C}$ for 30 seconds, $70^{\circ} \mathrm{C}$ for one minute, $72^{\circ} \mathrm{C}$ for one minute and final extension at $72^{\circ} \mathrm{C}$ during ten minutes.

- With a volume of $25 \mu \mathrm{L}$ a1/a2: Phoneutria 2X buffer (Phoneutria Biotecnologia e Serviços Ltda., Brazil), dNTPs $0.2 \mathrm{mM}, 0.3$ $\mathrm{mM} \mathrm{MgCl}_{2}, 0.4 \mathrm{pmol}$ a1/a2 primers, Taq polymerase $4 \mathrm{U}$ (Phoneutria Biotecnologia e Serviços Ltda., Brazil), $0.5 \mathrm{~mL}$ of DNA, 18.8 $\mathrm{mL}$ of water and a thermal cycler BIOER XP (BIOER Techonology Co. Ltda., China). The cycle conditions were $95^{\circ} \mathrm{C}$ for five minutes, 35 cycles at $95^{\circ} \mathrm{C}$ for 30 seconds, $55^{\circ} \mathrm{C}$ for 1.5 minute, $72^{\circ} \mathrm{C}$ for 1.5 minute and final extension at $72^{\circ} \mathrm{C}$ for ten minutes.

- With a volume of $25 \mu \mathrm{L}$ b1/b2: Phoneutria $2 X$ buffer (Phoneutria Biotecnologia e Serviços Ltda., Brazil), $0.2 \mathrm{mM}$ dNTPs, $0.3 \mathrm{mM} \mathrm{MgCl}$, 1 pmol a1/a2 primers, Taq polymerase $4 \mathrm{U}$ (Phoneutria Biotecnologia e Serviços Ltda.,
Brazil), $0.5 \mathrm{~mL}$ of DNA, $17.3 \mathrm{~mL}$ of water and thermal cycler BIOER XP (BIOER Techonology Co. Ltda., China). The cycle conditions were $95^{\circ} \mathrm{C}$ for five minutes, 35 cycles at $95^{\circ} \mathrm{C}$ for 30 seconds, $70^{\circ} \mathrm{C}$ for 1.5 minute, $72^{\circ} \mathrm{C}$ for 1.5 minute and final extension at $72^{\circ} \mathrm{C}$ for ten minutes.

- During PCR cycles, in the denaturation step, the temperature was raised up to $95^{\circ} \mathrm{C}$ for five minutes. In the following steps, it was maintained at $95^{\circ} \mathrm{C}$ for 30 seconds and in the annealing step, it was reduced to $70^{\circ} \mathrm{C}$ for one minute to $L$. chagasi, $55^{\circ} \mathrm{C}$ for $L$. amazonensis and $70^{\circ} \mathrm{C}$ for $L$. braziliensis. During polymerization, the temperature was reduced to $72^{\circ} \mathrm{C}$ for 90 seconds for all species. Finally, PCR cycles were repeated 40 times for L. chagasi and 35 times for L. amazonensis and L. braziliensis.

The electrophoresis was performed on agarose gel with $2 \%$ tris-acetate-EDTA (TAE) $1 \mathrm{X}$ buffer, pH 8.0, $80 \mathrm{~V}$ and $400 \mathrm{~mA}$ (0.04 M Tris-acetate, EDTA 0.001 . The gels were stained with ethidium bromide $(0.5 \mathrm{mg} / \mathrm{mL})$ and visualized with ultraviolet light.

When all the PCR conditions for Leishmania DNA amplification were established, and the primers RV1 and RV2 specific to the species L. (L.) chagasi and a1/a2 specific to $L$. (L.) amazonensis were tested, the results were not satisfactory, since they did not permit the amplification of DNA from the saliva of the tested patients. However, when the primers b1/ b2, specific to L. (V.) braziliensis were employed, PCR was successful in the detection of DNA in

Table 1. Primers and DNA controls for the species L. (L.) chagasi, L. (L.) amazonensis and L. (V.) braziliensis used in PCR for identification of Leishmania DNA in the saliva of patients with ACL

\begin{tabular}{|c|c|c|c|c|}
\hline Species & & Primer & DNA control & $\begin{array}{c}\text { Expected } \\
\text { product }\end{array}$ \\
\hline \multirow{2}{*}{ L. (L.) chagasi } & RV1 & CTTTTCTGGTCCCGCGGGTAGG & \multirow{2}{*}{ MHOM/BR/74/PP/75 } & \multirow{2}{*}{$145 \mathrm{bp}$} \\
\hline & $\mathrm{RV} 2$ & CACCTGGCCTATTTTACACCA & & \\
\hline \multirow{2}{*}{$\begin{array}{c}\text { L. (L.) } \\
\text { amazonensis }\end{array}$} & a1 & TGCGAGGATAAAGGGAAAGAA & \multirow{2}{*}{ IPLA/BR/67/PH8 } & \multirow{2}{*}{$62 \mathrm{bp}$} \\
\hline & a2 & GTGCCCTGACTTGCATGTCTA & & \\
\hline \multirow{2}{*}{$\begin{array}{c}\text { L. }\left(V_{.}\right) \\
\text {brazilienses }\end{array}$} & b1 & GTGGGCGTATCTGCTGATGAC & \multirow{2}{*}{ MHOM/BR/75/M2903 } & \multirow{2}{*}{$103 \mathrm{bp}$} \\
\hline & b2 & CAAAAAGCGAGGGACTGCGGA & & \\
\hline
\end{tabular}




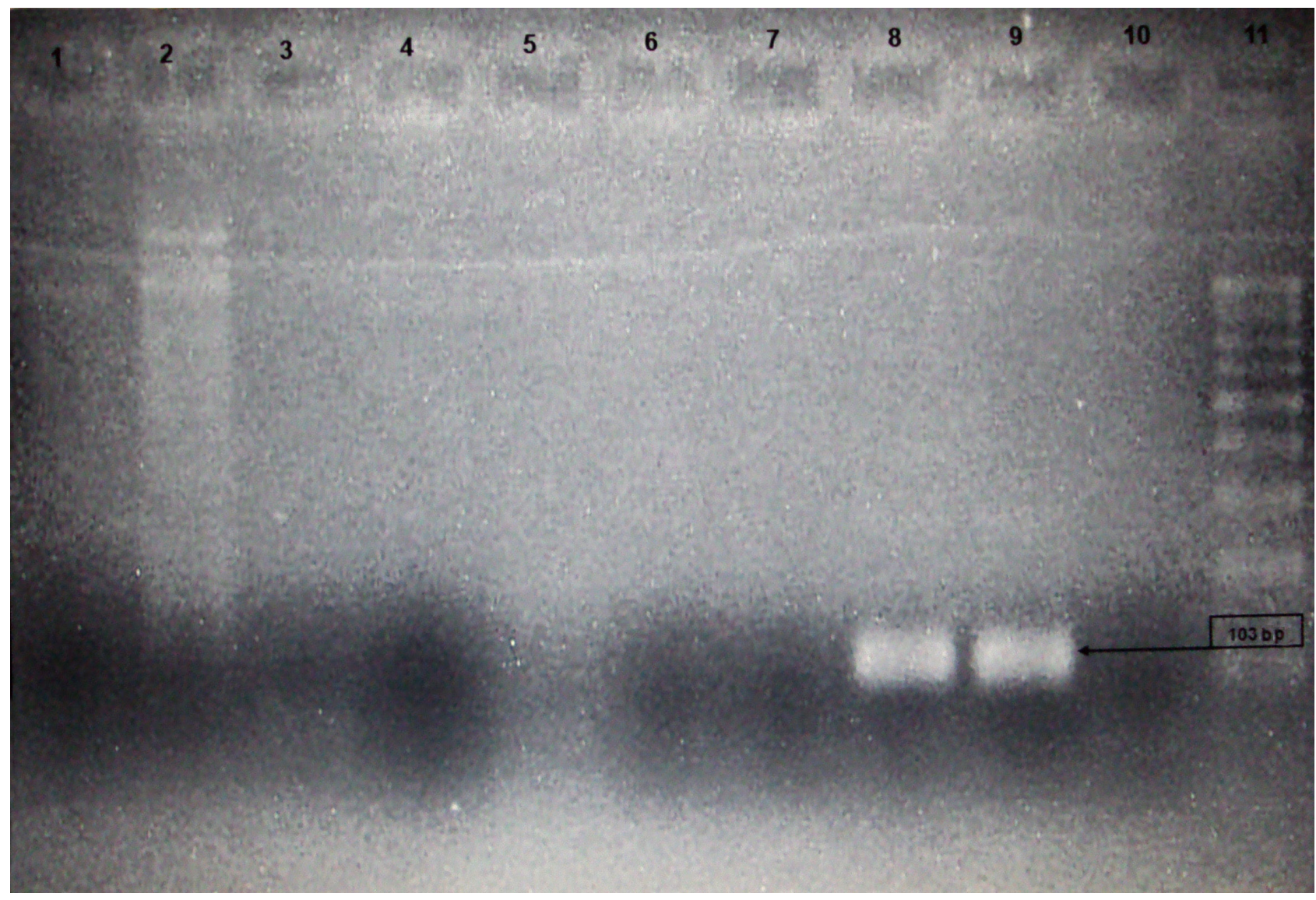

Figure 2. PCR products from samples of oral fluid showing amplification by PCR of $L$. (V.) braziliensis (lane 8) obtained from a patient with American cutaneous leishmaniasis (amplification of $103 \mathrm{bp}$ ). The lanes 1, 3, 4, 5, 6 and 7 identify samples of patients with visceral leishmaniasis; in lane 2, a sample of a healthy control; in lane 9, a positive control; in lane 10, a negative control; lane 11 is the marker that determines the pattern of the molecular size - $103 \mathrm{bp}$.

the saliva of the patient with ACL (Figure 2). In $\mathrm{ACL}$, this species is very frequent and skin and mucosal samples subjected to PCR enables the identification of 39.2 to $93.8 \%$ of the parasite prevalence $(3,9,11)$.L. (V.) braziliensis DNA was also detected in the salivary fluid of two more patients with mucocutaneous leishmaniasis, but these results are still under evaluation.

The PCR technology is very flexible, allowing a series of adaptations that permits its use in the analysis of a wide variety of substrates. In the literature, there are numerous studies and reports describing the use of salivary secretion as a potential biological fluid sample for laboratory tests. Its diagnosis value has been corroborated by studies using body fluids, whereby it is possible to analyze specific substrates that are important for clarifying disease diagnosis (12, 13). Oral fluids may be used for detection and characterization of microorganisms by molecular tests on the grounds of providing a convenient source of microbial DNA (12-14). An important aspect to consider is that saliva collection is simple and noninvasive. It does not involve critical biological material due to the fact that it is dispensed directly from the mouth into the tube used for transportation. It is not complex, and decreases the possibility of contamination and technical failures since it does not depend on the intervention of technicians in this phase. Among the other advantages of using saliva as a substrate is its easy access to the mouth with a noninvasive procedure $(12,13,15)$. When compared with samples of blood and urine, the transportation and preservation of salivary substrates are also simpler and cheaper (15). The present study can be considered pioneering, since it was the first to be able to detect the parasite $L$. (V.) braziliensis in the saliva sample of a patient with ACL utilizing PCR. To validate this molecular method employing saliva as a substrate in 
the diagnosis of leishmaniasis, the research continues with a larger number of cases.

\section{ACKNOWLEDGEMENTS}

We are indebted to the Foundation to Support the Development of Education, Science and Technology of the State of Mato Grosso do Sul (FUNDECT).

\section{COPYRIGHT}

(c) CEVAP 2011

\section{SUBMISSION STATUS}

Received: October 10, 2010.

Accepted: December 15, 2010.

Abstract published online: January 25, 2011.

Full paper published online: February 28, 2011.

\section{CONFLICTS OF INTEREST}

There is no conflict.

\section{FINANCIAL SOURCE}

The Foundation to Support the Development of Education, Science and Technology of the State of Mato Grosso do Sul (FUNDECT) provided the financial grants.

\section{ETHICS COMMITTEE APPROVAL}

The present study was approved by the Ethics Committee on Research of the Federal University of Mato Grosso do Sul, process number 1152/08.

\section{CORRESPONDENCE TO}

FÁTIMA HERITIER CORVALAN, Faculdade de Odontologia, Universidade Federal do Mato Grosso do Sul, Campo Grande, MS, Brazil. Phone: +55 67 33457381. Phone: +55 679983 5499. Email: fhcorvalan@yahoo.com.br.

\section{REFERENCES}

1. Cury PR, Furuse C, Araújo NS. Technique and application of reaction polymerase chain in the dental field. J Dent Araçatuba. 2005;26(2):34-9.

2. Singh S. New developments in diagnosis of leishmaniasis. Indian J Med Res. 2006;123(3):31130.

3. Garcia FCB, Dos Santos SSR, Chociay MF, Medeiros ACR, Roselino AMF. Subsidiary methods for the diagnosis of American tegumentar leishmaniasis (ATL): comparison of sequencing of DNA and PCR-RFLP for identification of Leishmania species in skin sample. An Bras Dermatol. 2005;80(3):339-44.
4. Mimori T, Sasaki J, Nakata M, Gomez EA, Uezato H, Nonaka S, et al. Rapid identification of Leishmania species from formalin-fixed biopsy samples by polymorphism-specific polymerase chain reaction. Gene.1998;210(2):179-86.

5. Pirmez C, da Silva Trajano V, Paes-Oliveira Neto MP, da-Cruz AM, Gonçalves-da-Costa SC, Catanho M, et al. Use of PCR in diagnosis of human American tegumentary leishmaniasis in Rio de Janeiro, Brazil. J Clin Microbiol. 1999;37(6):1819-23.

6. Forkner CE, Zia LS. Viable Leishmania donovani in nasal and oral secretions of patients with Kala-azar and the bearing of this finding on the transmission of the disease. J Exp Med. 1934;59(4):491-9.

7. Romero GA, Sampaio RN, Macedo V de O, Marsden PD. Sensitivity of a vacuum aspiratory culture technique for diagnosis of localized cutaneous leishmaniasis in an endemic area of Leishmania (Viannia) braziliensis. Mem Inst Oswaldo Cruz. 1999;94(4):505-8.

8. Sampaio RNR, Andrade GB, Silva EA, Cuba CAC, Pereira AC. Comparative study of parasitological techniques for demonstration of amastigotes and primary isolation of promastigotes in American cutaneous leishmaniasis. An Bras Dermatol. 2002;77(5):557-61.

9. Mimori T, Matsumoto T, Calvopiña MH, Gomez EA, Saya H, Katakura K, et al. Usefulness of sampling with cotton swab for PCR-diagnosis of cutaneous leishmaniasis in the New World. Acta Trop. 2002;81(3):197-202.

10. Lima Júnior MS, Andreotti R, Dorval ME, Oshiro ET, Oliveira AG, Matos M de F. Identification of Leishmania species isolated from human cases in Mato Grosso do Sul, by means of the polymerase chain reaction. Rev Soc Bras Med Trop. 2009;42(3):303-8.

11. Camargo LB, Langoni H. Impact of leishmaniasis on public health. J Venom Anim Toxins incl Trop Dis. 2006;12(4):527-48.

12. Moura SAB, Gerb M, Medeiros AMC, Souto MF, Emiliano GBG, Sousa JMA. Identificação de Helicobacter pylori na saliva e biofilme dental. Int J Dentistry. 2004;3(2):349-52.

13. Tabak LA. A revolution in biomedical assessment: the development of salivary diagnosis. J Dent Educ. 2001;65(12):1335-9.

14. Wong DT. Salivary diagnostics powered by nanotechnologies, proteomics and genomics. Am J Dent Assoc. 2006;137(3):313-21.

15. Lawrence HP. Salivary markers of systemic disease: noninvasive diagnosis of disease and monitoring of general health. J Can Dent Assoc. 2002;68(3):170-4. 